\title{
A EDUCAÇÃO, REFORMAS CURRICULARES E AS PROPOSTAS DO BANCO MUNDIAL NO CONTEXTO PÓS-GOLPE (2016-2018)
}

\author{
Renata Valério Silva ${ }^{1}$, Jani Alves da Silva Moreira ${ }^{2}$ \\ ${ }^{1}$ Mestranda do Programa de Pós-Graduação em Educação da Universidade Estadual de Maringá - UEM, Maringá, PR. \\ E-mail: rehvalerio@gmail.com \\ ${ }^{2}$ Doutora em Educação pela Universidade Estadual de Maringá - UEM, Maringá, PR. Docente do Departamento de \\ Teoria e Prática da Educação e do Programa de Pós-Graduação em Educação na instituição Universidade Estadual de \\ Maringá - UEM, Maringá, PR.
}

\section{RESUMO}

O presente texto tem como objetivo analisar as propostas do Banco Mundial e o conceito de educação no governo de Michel Temer ${ }^{1}$ a fim de inquirir e elucidar as principais medidas políticas que permearam as reformas educacionais no Brasil, entre os anos de 2016 a 2018. Trata-se dos resultados de uma pesquisa exploratória qualitativa, na qual a metodologia adotada para desenvolvimento foi a análise documental. Utilizamos como fonte primária documentos selecionados do Banco Mundial (BM) e amparamos as análises a partir da compreensão do contexto histórico e seus determinantes. Os resultados evidenciam que há consonância entra as orientações do BM com as medidas tomadas nas reformas educacionais atuais no Brasil.

Palavras-chave: Educação. Políticas Educacionais. Reformas Educacionais. Pós-Golpe. Banco Mundial.

\section{EDUCATION, CURRICULAR REFORMS AND THE PROPOSALS OF THE WORLD BANK IN THE POST-SWELL CONTEXT (2016-2018)}

\begin{abstract}
The present text aims to analyze the proposals of the World Bank and the concept of education in the government of Michel Temer, in the period called by means of analyzes of the post-legal-parliamentary and mediatic coup, in order to investigate and elucidate the main These are the results of a qualitative exploratory research, in which the methodology adopted for development was documentary analysis. We used as primary source documents selected from the World Bank (WB) and supported the analyzes in authors that approach the theme. The results show that there is harmony between the WB guidelines and the measures taken in the current educational reforms in Brazil.
\end{abstract}

Keywords: Education. Educational Policies. Educational Reforms. Post-stroke. World Bank.

LA EDUCACIÓN, REFORMAS CURRICULARES Y LAS PROPUESTAS DEL BANCO MUNDIAL EN EL CONTEXTO POSTGOLPE (2016-2018)

\section{RESUMEN}

El presente texto tiene como objetivo analizar las propuestas del Banco Mundial y el concepto de educación en el gobierno de Michel Temer a fin de ofrecer respuestas y elucidar las principales medidas políticas que impregnaron las reformas educativas en Brasil entre los años 2016 a 2018. Se trata, de los resultados de una investigación exploratoria cualitativa, en la cual la metodología adoptada para el desarrollo fue el análisis documental. Utilizamos como fuente primaria documentos seleccionados del Banco Mundial (BM) y amparamos los análisis a partir de la comprensión del contexto histórico y sus determinantes. Los resultados evidencian que hay consonancia entra las orientaciones del BM con las medidas tomadas en las reformas educativas actuales en Brasil.

Palabras clave: Educación. Políticas Educativas. Reformas Educativas. Posgolpe. Banco Mundial.

\footnotetext{
${ }^{1}$ Assumiu o governo em 31 de agosto de 2016 (até a presente data), após o impeachment de Dilma Rousseff. 


\section{INTRODUÇÃO}

O presente texto tem como objetivo analisar as propostas e as recomendações do Banco Mundial (BM) no período de 2016 a 2018 a fim de identificar o conceito de Educação que permearam as atuais reformas políticas. Para dar conta do proposto, apresentamos em um primeiro momento, a compreensão acerca do período denominado de "pós-golpe jurídicoparlamentar e midiático" (ALVES, 2017, p. 134), com o intuito de compreender o contexto histórico da crise política, econômica e partidária vivenciada no Brasil após o impeachment de Dilma Vana Rousseff (1 de janeiro de 2011 - 31 de agosto de 2016). Em seguida, situa-se o BM no contexto de produção na fase do capitalismo internacional a fim de compreender as influências da sua base teórica pautada no Neoliberalismo e o papel do Estado nas políticas educacionais.

\section{MÉTODOS}

Os resultados apresentados nesse texto foram decorrentes de uma pesquisa exploratória e qualitativa desenvolvida no Grupo de Estudos e Pesquisas em Políticas Educacionais, Gestão e Financiamento da Educação (GEPEFI/CNPq). A metodologia adotada refere-se a um estudo de análise documental, com enfoque crítico e contextualizado à luz da Ciência da História. Nas análises aqui mediadas, questionamos, fundamentalmente, a visão da realidade educacional apresentada nos documentos do Banco Mundial selecionados para a investigação. Por meio de uma compreensão conflitiva, dinâmica e histórica da realidade, o proposto na investigação foi expor, mais do que as interpretações subjacentes nos documentos, os conflitos de interesses políticos e econômicos que permeiam a construção e a definição das reformas educacionais no país. Nesse sentido, a dimensão desta análise é histórica e considera-se que a política educacional é mais do que apenas um produto, mas um processo, pois na análise que se propõe conceitua-se a:

$$
\begin{aligned}
& \text { [...] Política enquanto } \\
& \text { sinônimo de disputa de } \\
& \text { poder. A política ou as } \\
& \text { políticas não são apenas as } \\
& \text { ações que emanam do } \\
& \text { Estado, mas devem ser } \\
& \text { entendidas como um } \\
& \text { processo político que } \\
& \text { envolve negociações na } \\
& \text { arena de luta das classes } \\
& \text { antagônicas, exigindo } \\
& \text { contestação e disputa } \\
& \text { entre grupos com } \\
& \text { interesses adversos } \\
& \text { (MOREIRA, 2018, p. 201). }
\end{aligned}
$$

As discussões assentam-se no panorama histórico atual, no qual se explicita a conjuntura do Estado e do Neoliberalismo no contexto de Mundialização do Capital. Para essa compreensão utilizamos as análises de Antunes (2017), Alves (2017), Saviani (2017). Com relação à análise documental, os documentos do BM selecionados foram os seguintes:

\begin{tabular}{|l|l|}
\hline \multicolumn{2}{|c|}{ Documentos do Banco Mundial } \\
\hline \multicolumn{1}{|c|}{ Título do documento } & Ano \\
\hline Prioridades y Estrategias para La Educacion & 1995 \\
\hline Um Ajuste Justo: Análise da eficiência e equidade do gasto público no Brasil & 2017 \\
\hline $\begin{array}{l}\text { Competências e empregos: uma agenda para a juventude: síntese de constatações, } \\
\text { conclusões e recomendações de políticas. }\end{array}$ & 2018 \\
\hline $\begin{array}{l}\text { Relatório sobre o Desenvolvimento Mundial- Aprendizagem para Realizar a Promessa da } \\
\text { Educação: síntese }\end{array}$ & 2018 \\
\hline $\begin{array}{l}\text { Por um ajuste justo com crescimento compartilhado: uma agenda de reformas para o } \\
\text { Brasil }\end{array}$ & 2018 \\
\hline
\end{tabular}

Fonte: Elaborado pelas autoras (2018)

Por último, concluímos a análise no qual se evidenciou um panorama de questões pertinentes acerca da educação, de suas políticas e de como as reformas educacionais tem sido conduzidas no país por meio da influência e das recomendações do BM.

\section{RESULTADOS}

O período denominado de "pós-golpe jurídico-parlamentar e midiático" foi assim designado por Alves (2017, p. 134) para se referir à própria natureza do golpe de 2016 no país. Diante desse espectro instaurou-se um panorama 
de crise econômica e política metabolizada por transformações e inquietações também no cenário educacional. Imediatamente diversas mudanças na equipe de gestão do Ministério da Educação (MEC) ocorreram, como também medidas foram tomadas e desencadeadas como reformas educacionais. $\mathrm{Na}$ tentativa de compreender e analisar esse contexto, Antunes nos apresenta que:

Já nas eleições de outubro de 2014 era possível perceber uma redução do apoio das frações burguesas ao governo Dilma, uma vez que o quadro recessivo antecipava a necessidade de mudanças profundas em sua política econômica para ajustar-se ao novo cenário. Não foi por outro motivo que, imediatamente após a vitória eleitoral, em janeiro de 2015, Dilma implementou um ajuste fiscal profundamente recessivo que, além de ampliar descontentamento empresarial, aumentou também os descontentamentos em todas as classes sociais ainda que frequentemente por motivos opostos (ANTUNES, 2017, p.57).

O descontentamento empresarial levou essa classe a procurar saídas para este momento, o país enfrentou períodos de instabilidade econômica e política, culminados com uma mídia coadjuvante desse processo, pondera o autor. Como o impeachment está previsto na Constituição de $1988^{2}$ do país, gestou-se a "alternativa ideal": deflagrar um golpe com aparência legal, constitucional, conforme a análise de Antunes (2017). Um golpe que, contando com o decisivo apoio da grande mídia dominante, "assumiu a feição de um não golpe" (ANTUNES, 2017, p.58).

\footnotetext{
${ }^{2} \mathrm{O}$ artigo 85 estabelece quais são os atos de crimes de responsabilidade do Presidente da República. Outras bases legais do impeachment se encontram nos artigos art. 51, I; art. 52; art. 86, § 10, II, § 20. Essas normas estão na Lei 1.079, de 1950, que foi recepcionada, em grande parte, pela CF/1988.
}

Estava posto o novo cenário brasileiro, um governo que chegou ao poder com o apoio do empresariado, da justiça e da mídia, apoiados também por movimentos sociais liderados por partidos da direita brasileira e por frentes parlamentares de base conservadora e fundamentalista. Esse engendramento na resolução dos encaminhamentos propostos para resolver a crise política no país teve o forte apoio no pensamento social das classes, pois "[...] as frações dominantes chegaram a um primeiro consenso: [...] em época de crise quem vai pagar com o ônus dessas perdas? Será, como sempre, a classe trabalhadora" (ANTUNES, 2017, p.58).

Instaurado este dissenso, iniciou-se um processo de reformas que abalaram o Estado Democrático de Direito e, também, desencadearam-se mudanças austeras nos setores sociais e nos serviços públicos. Aborda Alves (2017) que "[...] o processo de ruptura da institucionalidade democrática ocorrida no Brasil em 2016 é a culminação do longo movimento histórico de reação às políticas dos governos neodesenvolvimentistas" (ALVES, 2017, p.138).

[...] Enfim, no palco da história sinistra do golpe de 2016 no Brasil operam, de modo intenso, interna e externamente, forças econômicas, políticoideológicas e geopolíticas ocultas - e algumas delas, não tão ocultas assim que coordenam os interesses estratégicos do Departamento de Estado norte-americano, o polo hegemônico do Império neoliberal, com elementos (partidos, movimentos sociais, think tanks e meios de comunicação de massa) da oposição neoliberal, reacionária e oligárquica brasileira (a direita fisiológica e ideológica que ocupou com o impeachment da Dilma, o governo Temer) (ALVES, 2017, p. 139).

O período de instabilidade tomou conta do campo educacional $e$ as reformas educacionais com bases neoliberais se intensificaram por meio de ações e medidas austeras pautadas no crescimento de 
conveniamentos, parcerias público e privado, ajustes e cortes de verbas públicas na área social, ou seja, o que aqui consideramos como "formas específicas de privatização", nas suas dimensões de privatização da gestão educacional, privatização da gestão escolar, privatização do currículo e a privatização da oferta educacional (ADRIÃO, 2018).

As orientações norte-americanas por meio de documentos produzidos pelo Banco Mundial se intensificaram na sua aplicabilidade, pois documentos encomendados e exclusivos para o Brasil foram produzidos por consultores do BM, no período proposto para as análises dessa pesquisa. Em sua maioria, a focalização das orientações permearam os ajustes dos gastos e das contas públicas. Evidentemente, o contexto econômico do neodesenvolvimentismo e sua instabilidade determinaram a aparência e a essência das rígidas medidas políticas, conforme elucida Alves:

É importante que se diga que a taxa de lucratividade da economia brasileira vinha caindo pelo menos desde $2010 . \quad$ A instabilidade política, a degradação das contas públicas, falta de investimentos privados e a política de ajuste fiscal do Ministro Lévy indicado por Dilma aprofundaram a recessão da economia brasileira em 2015, criando as condições propícias para o Golpe de 2016. Ao chegar nos seus limites, O neodesenvolvimentismo implodiu, sendo adotado uma nova agenda de reestruturação capitalista no Brasil. $\mathrm{Na}$ verdade, aproveita-se da crise do capitalismo para construir uma nova matriz do gasto público no Brasil e um patamar de exploração da força de trabalho e degradação social do povo brasileiro capaz de propiciar novas condições para a acumulação do capital e crescimento da economia brasileira. $\mathrm{Na}$ verdade, trata-se da busca de um "crescimento sem desenvolvimento", onde se deve elevar o nível da luta de classes, a concentração de renda e a desigualdade social como temos verificado nos países capitalistas centrais (ALVES, 2017, p.146-147).

O neodesenvolvimentismo " $[. .$. contempla prioritariamente os interesses da grande burguesia interna" (BOITO JUNIOR, 2016, p.155), o autor concluiu que:

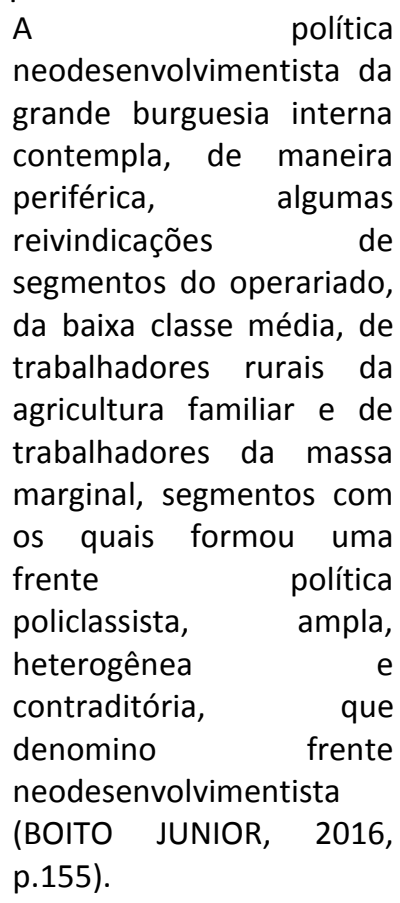

Essa característica da política
neodesenvolvimentista em atender reivindicações de classes minoritárias desagradou o empresariado brasileiro, que por sua vez não admitia o avanço de minorias que lutam por direitos sociais e pressionam o Estado a arcar com suas responsabilidades quanto aos serviços públicos. Serviços esses que estão em risco frente a uma onda de privatizações advindas do neoliberalismo. Os governos de Luís Inácio Lula da Silva (2003-2010) e Dilma Rousseff (20112016) são reconhecidos por praticar uma política neodesenvolvimentista, o que de certa forma, motivou uma forte resistência aos ideais neoliberais.

O cerne do neoliberalismo resulta na política econômica em que se visa menos intervenção do Estado nos serviços públicos sociais, a fim de impulsionar ações da iniciativa privada, incitando a ideia de que o Estado é 
insuficiente para a administração dos serviços públicos e precisa do empresariado para o desenvolvimento econômico sustentável da sociedade. Na visão de Ball (2014), o neoliberalismo assume diferentes dimensões no âmbito econômico, político e cultural. Assim, atua a favor ou contra o Estado, cria ou não novas formas de governar.

Ante às crises do capital, as ideias neoliberais são apresentadas como via de solução para superá-las objetivando a manutenção do sistema capitalista. O neoliberalismo é "uma corrente de pensamento e uma ideologia, isto é, uma forma de ver e julgar o mundo social" (MORAES, 2001, p. 3). O objetivo neoliberal é propor um "modelo ideal" de organização social e econômica, visando menos intervenção estatal nas políticas sociais (educação, saúde, moradia, previdência e segurança). Articula suas ideias demonstrando o atual contexto de precarização dos serviços públicos, organiza um pacote de medidas com soluções imediatas que atrai a atenção da sociedade, justamente por propor soluções imediatistas e realiza um discurso convincente com um viés atrativo, porém, nas entrelinhas propõe a articulação entre os setores público e privado, de modo que sustente a classe dominante e favoreçam empresas privadas.

O modelo ideal em que essa ideologia se baseia significa "[...] reformas orientadas para e pelo mercado, "libertando" o capital dos controles civilizadores que the foram impostos [...]" (MORAES, 2001, p. 14) e para atingir o objetivo de diminuir a intervenção estatal nos serviços públicos utilizam medidas como,

[...] privatizar empresas estatais e serviços públicos, por um lado; por outro, "desregulamentar", ou antes, criar novas regulamentações, um novo quadro legal que diminua a interferência dos poderes públicos sobre os

empreendimentos

privados. O Estado deveria transferir ao setor privado as atividades produtivas em que indevidamente se metera e deixar a cargo da disciplina do mercado as atividades regulatórias eu em vão tentara estabelecer (MORAES, 2001, p.18).
Diante deste cenário, a educação como um serviço público encontra-se em uma linha tênue entre o público versus o privado. Após apresentar um cenário apocalíptico da conjuntura econômica a ideia de privatizar remete como a via de solução mais cabível. Existe um consenso entre os neoliberais conservadores sobre a crise no sistema educacional e "[...] na construção desse consenso desempenharam um papel central as agências internacionais, em especial, o Banco Mundial [...]" (GENTILI, 1996, p.7).

A educação perde seu princípio de formar um indivíduo social e critico capaz de repensar e que preze o bem coletivo "[...] Ela encontra o seu preciso limite no exato momento em que o indivíduo se lança ao mercado para lutar por um emprego" (GENTILI, 1996, p.8), a educação tornase então apenas uma ferramenta que contribui para o ingresso no mercado de trabalho, pois:

$$
\begin{aligned}
& \text { [...] no âmbito das } \\
& \text { políticas públicas de } \\
& \text { educação, identificamos } \\
& \text { claros indícios de uma } \\
& \text { prática neoliberal, } \\
& \text { principalmente no tocante } \\
& \text { ao foco no atendimento às } \\
& \text { demandas do mercado de } \\
& \text { trabalho, não valorizando, } \\
& \text { na prática, a formação } \\
& \text { integral do aluno, e do ser } \\
& \text { humano com cidadão } \\
& \text { (ALVES, 2011, p.1) }
\end{aligned}
$$

De acordo com Alves (2011, p. 2) "O Neoliberalismo representa a face mais cruel do modelo capitalista", formando uma sociedade cada vez mais individualista. Na visão neoliberal "o sistema educacional deve promover [...] empregabilidade" (GENTILI, 1996, p. 8), ou seja, moldar o indivíduo com o objetivo de torná-lo "flexível de adaptação individual às demandas do mercado de trabalho. A função "social" da educação esgota-se neste ponto" (GENTILI, 1996, p. 8). Neste aspecto as políticas educacionais estão em consonância com as orientações do BM, que propõe uma educação para todos, garantido legalmente, mas não subsidia a inserção de todos nas escolas, mediante uma proposta emancipatória. Na visão de Saviani (2017) também é possível fundamentar-se nas seguintes análises que evidenciam a contradição:

Nessa perspectiva a
educação adere um novo
caráter "Nesse novo


contexto a educação assume uma função explicitamente política. A escola passa a ser entendida como um instrumento para transformar os súditos em cidadãos, portanto, um instrumento de participação política, a via efetiva para se implantar a democracia. Tratava-se de uma proposta que representava os anseios não apenas da classe dominante, mas também da classe dominada. Eis aí o caráter hegemônico da burguesia: seus interesses são expressos de modo a abarcar também os interesses das demais classes; a ideologia liberal se torna consenso. Isso, porém, não ocorre de forma tranquila, linear, mas de maneira contraditória, conflituosa" (SAVIANI, 2017, p. 223224).

Aliada ao neoliberalismo, no contexto atual é possível identificar que o ideário neoconservador também se intensificou nas reformas, principalmente na área educacional e no âmbito dos direitos humanos. 0 neoconservadorismo ${ }^{3}$ e o fundamentalismo ${ }^{4}$

\footnotetext{
${ }^{3}$ Marilena Chaui discorre sobre $A$ nova classe trabalhadora brasileira e a ascensão do conservadorismo, pontuando que houve grandes transformações na composição da sociedade brasileira, afirmando que "a e classe média tende a ser fragmentada, raramente encontrando um interesse comum que a unifique" (CHAUI, 2016, p.19). Além disso, afirma que o sonho da classe média "é tornar-se parte da casse dominante; seu pesadelo, tornar-se proletária" (CHAUI, 2016, p.20). Para que o sonho seja realizado e o pesadelo espantado é preciso "ordem e segurança" com isso a classe média "ideologicamente conservadora e reacionária, e seu papel social e político é assegurar a hegemonia ideológica da classe dominante" (CHAUI, 2016, p.20).

É importante destacar que o conservadorismo clássico "podem ser encontradas no século XVIII [...] A ideia central era "conservar" valores e instituições - como a monarquia e a religião cristã considerados como pilares fundamentais da civilização e da cultura ocidentais" (ALMEIDA, 2018, p.29). Almeida (2018) conceitua que o neoconservadorismo "manifestação bem mais recente surgida em reação às transformações socioeconômicas da primeira metade do século XX" (ALMEIDA, 2018, p.29).O neoconservadorismo buscam a retomada de valores que "feito em nome de um igualitarismo artificialmente criado pela intervenção estatal" pois, "o Estado sempre será, de um jeito ou de outro, uma força conservadora, na medida em que precisa atuar na preservação das formas sociais básicas do capitalismo" (ALMEIDA, 2018, p.32).
}

estão presentes nas atuais políticas com características retrógradas que estão em andamento no país, como é o caso das propostas da Escola Sem Partido ${ }^{5}$, que sugere excluir ideologias que fazem oposição com o discurso do governo e também a neutralidade política na sala de aula.

O discurso da retomara dos "valores tradicionais" ganhou espaço nas eleições de 2018, com o discurso de que é preciso retomar ao tradicional como moral para que a sociedade supere a crise econômica instaurada no país. Pode-se perceber que na conjuntura atual os valores morais e tradicionais, baseados em ações privadas estão aliados a um Estado denominado de funcional (PMDB, 2015), no qual as instituições escolares são reduzidas em atender ao mercado, pois a defesa é de que "[...] a sociedade capitalista, em que pesem suas contradições e especificidades, possui algumas relações que devem ser necessariamente conservadas, a fim de que o capitalismo possa se reproduzir" (GALLEGO, 2018, p. 31)

Como amparo da retomado dos "valores tradicionais" "[...] o fundamentalismo religioso, que, em nome de Deus e da verdade absoluta revelada, anula qualquer possibilidade de debate [...]" (GALLEGO, 2018, p. 10). Há uma forte

\footnotetext{
${ }^{4} \mathrm{O}$ fundamentalismo religioso prega uma verdade absoluta em nome de Deus não abrindo espaço para debates, colocando em risco a democracia (GALLEGO, 2018).

${ }^{5}$ O Programa Escola Sem Partido "culminou na apresentação de projetos de lei na Câmara dos Deputados, no Senado, em assembleias legislativas estaduais e em câmaras municipais. Como movimento, nasceu em 2004 da iniciativa do advogado paulista Miguel Nagib, então colaborador do Instituto Milenium. [...] O primeiro projeto de lei ESP foi proposto em 2014 pelo deputado estadual Flávio Bolsonaro (PSC) na Assembleia Legislativa do Rio de Janeiro, a partir de modelo elaborado por Nagib" (CUNHA, 2016, p.35). Um programa que visa tirar a liberdade de expressão dos professores de dentro da sala de aula "As páginas do movimento ESP e de seus apoiadores trazem exemplos em geral caricatos de professores que usam a sala de aula como espaço de doutrinação político-ideológica" (CUNHA, 2016, p.36). "A denúncia da doutrinação político-ideológica de caráter "petista" e/ou "marxista", é um recurso retórico conhecido como jogo da meia-verdade. Ele consiste em persuadir o interlocutor a crer nela mediante a apresentação de provas (ex: relatos, vídeos, impressos) que a corroboram, ao mesmo tempo em que se escondem provas contrárias. Esse recurso retórico é uma falácia difícil de ser desmascarada pelo ouvinte ou pelo leitor que não tem acesso ao conjunto das informações relativas à questão em jogo" (CUNHA, 2016, p.36). Um projeto que deixa evidente que não busca uma "escola sem partido" mas uma escola partidária condizente com o governo que a classe dominante e aqueles que contrariarem essa ideologia será "punido", um projeto que visa apagar a ideologia marxista. "Os projetos de lei que pretendem impor o Programa ESP têm como alvo vedar a prática nas salas de aula de doutrinação política e ideológica bem como a veiculação de conteúdos ou a realização de atividades que possam estar em conflito com as convicções religiosas ou morais dos pais ou responsáveis pelos estudantes. (CUNHA, 2016, p.39).
} 
influência religiosa no discurso de conservar a moral, a verdade é que este discurso religioso incumbe menos liberdade de expressão e repressão a tudo que contradiz com as ideias impostas pelos governadores.

Cabe evidenciar que tais acirramentos, tanto das medidas austeras que se intensificaram com o neoliberalismo, quanto as ideias fundamentalistas e neoconservadoras, encontram respaldo e legalidade em um Estado que cada vez mais tem se tornado menos democrático. É preciso deixar claro que o Estado brasileiro está vivenciando um momento de recessão democrática. Especificamente a partir de 2013, é perceptível no Brasil que as mudanças estão a aniquilar as conquistas democráticas construídas desde o período de redemocratização do país. A efetivação dos interesses privatistas estão intrinsecamente ligados aos interesses do mercado financeiro do capitalismo nacional e internacional, em novas ondas de expansão do pensamento conservador.

Os Estados Democráticos, segundo Levitsky; Ziblatt (2018, p. 194) estão "recuando em todo mundo", o que acena para um cenário onde as políticas estão marcadas "[...] por polarizações, por um distanciamento maior das convenções políticas não escritas e por crescentes guerras institucionais - em outras palavras, uma democracia sem grades de proteção" (LEVITSKY; ZIBLATT, 2018, p. 198). Esse contexto comprova o que outros autores afirmaram, de que o Brasil está vivenciando um momento de Estado de Exceção no país. Valim (2017), pautado nas análises de François SaintBonnet ${ }^{6}$ afirma que o vocábulo "Exceção" possui duas acepções, a saber:

[...] a primeira, por ele denominada "clássica", consistiria no momento durante o qual as regras jurídicas, previstas para períodos de calma, são transgredidas ou suspensas para o enfrentamento de um determinado perigo. Já a segunda, cujo grande representante seria

\footnotetext{
${ }^{6}$ Professor da Universidade Paris II Panthéon-Assas, na área de História das instituições, Introdução histórica ao direito e Lei das liberdades fundamentais. Desenvolve pesquisas sobre as liberdades civis, direito constitucional, instituições e doutrinas políticas e jurídicas em uma perspectiva histórica. Disponível em: http://institutvilley.com/Francois-Saint-Bonnet. Acesso em
} 01.12.2018.

\begin{abstract}
Giorgio
Agamben, apontaria para uma modificação profunda de certos sistemas jurídicos diante de perigos duráveis como o terrorismo. Em seguida, porém, o teórico francês descarta este segundo sentido sob o argumento de que a ideia de um "estado de exceção permanente" constituiria uma contradição em termos, na medida em que as exceções se tornaram regras (VALIM, 2017, p. 18).
\end{abstract}

De acordo com Valim (2017) o Estado de Exceção coloca em risco a democracia, pois "[...] a exceção, ao negar a lei, principal produto da soberania popular, toma de assalto a democracia. A pretensão de um governo impessoal das leis cede lugar ao governo pessoal dos homens (VALIM, 2017, p. 27). No caso do Brasil essa ameaça chegou por meio de "golpe institucional" colocando a frente um governo contraditório com a realidade brasileira, ampliando as ideias neoliberais e elevando a classe dominante, não obstante diminuindo direitos da classe trabalhadora, cenário esse que foi implementado com um discurso de "legalidade", como evidencia o autor:

De qualquer modo, é
fundamental desde já
compreender que o golpe
de estado de 2016 é tão só
um exemplo das múltiplas
exceções que, se já não
sepultaram por completo
o combalido Estado de
Direito brasileiro, estão
em vias de fazê-lo. Na
realidade, como restará
claro, o principal e mais
perigoso agente da
exceção no Brasil é o
Poder Judiciário (VALIM,
2017, p. 41).

Diante do apresentado destaca-se a ponderação de Saviani (2017) que retrata sobre a necessidade de uma resistência ativa quanto às ideias propostas pelos adeptos ao golpe jurídicoparlamentar e midiático, sempre mascaradas com propostas que atendem seus próprios 
interesses, surgem como medidas para 0 desenvolvimento. Como ressalta Saviani:

A função de mascarar os objetivos reais por meio dos objetivos proclamados é exatamente a marca distintiva da ideologia liberal, dada a sua condição de ideologia típica do modo de produção capitalista que introduziu, pela via do "fetichismo da mercadoria", a opacidade nas relações sociais (SAVIANI, 2017, p. 225).

As reformas educacionais são implantadas, entretanto permanecem os enfrentamentos e a resistência ativa na contramão desse processo. As propostas neoliberais, em oposição à realidade brasileira, são impostas por meio de medidas econômicas que inviabilizam e desconsideram a prioridade de uma educação pública, laica, de qualidade social para todos.

\section{DISCUSSÃO}

Perante as mudanças ocorridas no campo educacional no período "pós-golpe jurídicoparlamentar e midiático", é fundamental nos atentarmos ao cenário de reformas incessantes, pois:

$$
\begin{aligned}
& \text { Parte-se do desígnio de } \\
& \text { que as políticas } \\
& \text { educacionais atualmente } \\
& \text { em reforma no Brasil se } \\
& \text { constituem em } \\
& \text { representações históricas, } \\
& \text { com significações que } \\
& \text { expressam aspectos } \\
& \text { ideológicos produzidas no } \\
& \text { contexto de mundialização } \\
& \text { da economia, na fase de } \\
& \text { vigência da acumulação } \\
& \text { financeirizada, flexível e } \\
& \text { do neoliberalismo } \\
& \text { (MOREIRA, 2018, p. 205). }
\end{aligned}
$$

Trata-se de reformas com caráter ideológico neoliberal que restringem recursos para os serviços públicos enfatizando ações privadas. É importante validar que o conceito de reforma educativa apresenta dois aspectos: a padronização com ênfase a descentralização, em especial nas reformas ocorridas na educação de países da América Latina na década de 1990 e o de focalização e mercantilização da educação pública (SOUZA, 2003). Na visão de Moreira (2018), "[...] outro aspecto a considerar é que as mudanças políticas e econômicas geraram o que entendemos como sendo (anti)reformas atuais na educação pública brasileira (MOREIRA, 2018, p. 206).

Neste contexto a influencia internacional teve relevância, especialmente o Banco Mundial, que apresentou recomendações para as reformas educativas recentes, além de fornecer empréstimos para diversos setores. $\mathrm{O} \mathrm{BM}$ a fim de tornar disseminar suas ideias por meio de orientações não encontra dificuldade de realizar no Brasil mudanças estruturais, uma vez que, atende aos interesses econômicos e políticos (WAISMANN; CORSETTI, 2014).

Criado em 1944 com o objetivo de recuperar a economia dos países devastados pela Segunda Guerra Mundial (1939-1945), o BM teve como missão inicial recuperar o setor econômico. Durante 50 anos a atuação do banco impulsionou o setor industrial dos países membros. Essa configuração foi modificada com a gestão de McNamara $^{7}$ em 1968, que por sua vez se debruçou em erradicar a pobreza por meio de acordos estruturais que alterasse as configurações educacionais dos países mais afetados pela pobreza (MOREIRA; SILVA. 2016).

Ao longo das mudanças econômicas mundiais houve uma reorganização de prioridades do banco, que não deixou de conceder empréstimos do tipo convencional, mas passou a estabelecer acordos com os países periféricos com orientações para reformas educativas. Com uma intervenção consentida, o BM não encontrou obstáculos para atuar com direções às reformas no Brasil, como salientam Waismann; Corsetti (2014) ao explicitarem que diante do contexto de reforma do estado nos anos 90 ficou evidente que o:

[...] redirecionamento do
Estado brasileiro é
instruído pelas agências
multilaterais, que são
operadoras

\footnotetext{
${ }^{7}$ Robert McNamara ocupou o cargo de secretário de Defesa dos EUA durante os governos de John F. Kennedy e Lyndon B. Jonhson. Ele ficou conhecido como um dos principais arquitetos da estratégia americana na guerra do Vietnã entre os anos de 1961 e 1968. Em 1968, ele deixou a pasta e assumiu a Presidência do Banco Mundial até 0 ano de 1981 (PEREIRA, 2010). Disponível em http://www.scielo.br/pdf/topoi/v11n21/2237-101X-topoi-11-2100260.pdf
} 
pensamento neoliberal e concentram a hegemonia política e econômica. Suas orientações e ações mediadoras são seguidas por compartilhamento de visão de mundo entre as elites locais e as elites dos países (ditos) desenvolvidos por meio de uma intervenção consentida (WAISMANN; CORSETTI, 2014, p. 334).

A atuação do BM na visão de Shiroma; Moraes; Evangelista (2011) tem sido essencialmente norte-americana. Salientam que são cinco os países que definem as políticas preconizadas pelo $\mathrm{BM}$ :

[...] EUA, Japão, Alemanha, França e Reino Unido. Esses países participam com 38,2\% dos recursos do Banco. Entre eles, os EUA detêm em torno de $20 \%$ dos recursos gerais e o Brasil aproximadamente $1,7 \%$. A liderança norteamericana se concretiza também com a ocupação da presidência e pelo poder de veto que possui. $\mathrm{Na}$ verdade $\mathrm{o}$ Banco Mundial tem sido auxiliar da política externa americana (SHIROMA; MORAES; EVANGELISTA, 2011, p. 61).

No ano de 1995, o BM publicou seu primeiro documento com orientações para a educação, o documento com o título Prioridades y Estrategias para la Educación (1995) propunha mudanças na configuração da educação estabelecendo que era preciso,

1. Dar más prioridad a la educaión; 2. Prestar más atención a los resultados; 3. Centrar La inversión pública em La enseñanza básica, recurriendo al mismo tiempo em mayor medida AL financiamiento familiar para La enseñanza superior; 4. Prestar más atención a la equidade; 5 . Dar más participación al grupo familiar; 6. Dar más autonomia a las instituciones ${ }^{8}$ (BANCO MUNDIAL, 1995, p. XXII$X X V I)$.

O documento citado enfatiza o Ensino Fundamental como primordial para o indivíduo a fim de que esse tenha o mínimo para o ingresso no mercado de trabalho, funções básicas como ler e escrever. O professor, a estrutura física, material didático são elementos que aparecem como fundamentais para um padrão mínimo de qualidade na educação.

Há também uma discussão presente neste documento que propõe a realocação dos recursos destinados a educação. Nas entrelinhas, o discurso realizado recomenda que os egressos das universidades públicas contribuam com um valor a ser decidido por consentimento entre o BM e o país que adotar essa medida. Além disso, indica que é preciso investir mais nas séries iniciais e desresponsabilizar quanto ao investimento no Ensino Superior. Em linhas gerais, pode-se perceber que o documento recomenda uma política de equidade, focalização na pobreza, privatização dos serviços públicos, participação e parcerias (BANCO MUNDIAL, 1995).

A década de 1990 ficou marcada pelas reformas educacionais que foram enfatizadas por meio do discurso em reorganizar o sistema econômico culpabilizando a educação pelas crises geradas e por resultados que não se efetivaram. Há uma coerência de discurso da classe dominante brasileira e do BM em que o Brasil gerencia inadequadamente os recursos para a educação, sendo essa um serviço social visto como gasto proveniente da receita pública e não como investimento, enquanto aplicação de capital como expectativa futura de um desenvolvimento humano.

$O$ atual governo de Michel Temer instaurou um período de reformas educacionais com caráter neoliberal, acatando as orientações do Banco Mundial. Diferente de outros documentos publicados pelo Banco Mundial, o documento Um Ajusto Juste: Análise da eficiência e equidade do gasto público no Brasil, publicado em novembro de 2017, foi encomendado pelo

\footnotetext{
${ }^{8} 1$ Dar mais prioridade à educação; 2 Dar mais atenção aos resultados; 3 Centralizar o investimento público na educação básica, recorrendo, ao mesmo tempo, no desempenho do ensino superior; 4 Prestar mais atenção à equidade; 5 Aumentar a participação do grupo familiar; 6 Dar mais autonomia para as instituições. 15 Destacamos que o
} 
atual Governo Federal com o propósito de atingir mudanças por meio de ajustes estruturais e [...] realizar uma análise aprofundada dos gastos do governo, identificar alternativas para reduzir o déficit fiscal a um nível sustentável, e ao mesmo tempo, consolidar os ganhos sociais alcançados nas décadas anteriores (BANCO MUNDIAL, 2017).

O BM ao propor no documento a análise dos gastos do governo incluem propostas para a educação e, por sua vez, aos agentes que atuam nela. De acordo o documento publicado "O Governo Brasileiro gasta mais do que pode e, além disso, gasta mal" (BANCO MUNDIAL, 2017, p. 7), a redução dos gastos é uma "condição necessária" para que se faça o exercício de "priorização", assim o Brasil finalmente conseguirá equilibrar sua dívida pública que vem acumulando ano a ano. Os documentos possuem o desígnio de apresentar soluções para a crise econômica em que se encontra o atual cenário brasileiro.

O objetivo é adequar a economia brasileira a um padrão imposto pelo BM, cortando gastos vistos pela ótica do BM como um dinheiro mal gasto, inclusive na área da educação. Nesse sentido, propõem a privatização do ensino superior e a diminuição do salário dos professores, aumentando o número de alunos por sala para evitar a contratação de novos docentes (BANCO MUNDIAL, 2017).

De acordo com Amaral (2017) as informações apresentadas pelo BM não trazem comprovação e não foram apuradas com vistas a realidade brasileira, sendo assim, há uma certa incoerência na abordagem exibida. Neste caso, por ser um documento encomendado há de convir que há uma tendência de preservar o Governo Federal e suas ações, alegando que essas estão em prol do desenvolvimento brasileiro.

Pode-se perceber que há recorrência nas recomendações do BM com relação ao cenário atual, no qual busca-se "velhas" roupagens trazidos na década de 1990. Como já exposto no documento Prioridades y Estrategias para la Educacion (1995) há uma exigência de que a educação seja capaz de transformar o setor econômico, assim como nos discursos produzidos neste período de mudanças, no qual a educação é considerada um instrumento de alívio da pobreza. De acordo com as análises de Pansardi (2009):

A educação é vista da ótica de um banco, com o olhar de um financista, de um economista [...]. A escola é uma fornecedora de serviços, uma empresa. Sem compreender a especificidade da sala de aula e da aprendizagem, vistas como uma caixa preta impenetrável, o $\mathrm{BM}$ se volta para os insumos externos que qualificam ou não o produto final: o aluno (PANSARDI, 2009, p. 9).

Diante do cenário caótico economicamente produzido pelo capital, a perspectiva neoliberal é a elaboração de políticas paliativas, em que exibem melhorias emergenciais, mas não definitivas, "[..] por isso, em muitos países submetidos a programas de ajuste neoliberal, as políticas sociais são praticamente reduzidas a programas de socorro à pobreza absoluta" (MORAES, 2001, p. 37). As políticas educacionais neste sentindo, surgem para suprir as mazelas do capital, como via de solução da erradicação da pobreza.

As análises realizadas pelo BM nesse período de transição de governo, pós-golpe, tem unicamente uma visão economicista, que se encontra baseada em demandas elitistas, no qual desconsidera a realidade da educação brasileira. O descaso com a educação é nítido frente ao abandono de escolas e universidades, desvalorização dos professores, aumento dos investimentos para processos privatizantes nos sistemas públicos de educação. $O$ documento de forma geral apresenta recomendações com a ênfase nas categorias políticas de eficiência, equidade, redução e ajustes de gastos, privatização e focalização (BANCO MUNDIAL, 2017).

Ao propor que "Os gastos públicos com o ensino superior também são altamente ineficientes, e quase $50 \%$ dos recursos poderiam ser economizados" (BANCO MUNDIAL, 2017, p. 121) é posto em jogo a eficiência do Estado enquanto administrador dos recursos destinados a educação, enfatizando assim a desvalorização do ensino público brasileiro.

Outro documento recente do BM, intitulado Competências e empregos: uma agenda para a juventude: síntese de constatações, conclusões e recomendações de políticas (2018), apresenta um tópico "Resultados 
Educacionais e Motivação para Investir em Capital Humano", no qual apresenta questões sobre empregabilidade e educação enfatizando que existe um quebra-cabeça que precisa ser desvendado quanto a ausência de bons resultados na educação na economia do país. $\mathrm{Na}$ visão do BM essa questão se dá mediante três aspectos: "[...] uma demanda por mão de obra fortemente distorcida e com um viés para procurar mão de obra não qualificada, a baixa qualidade do sistema educacional e percepções incorretas sobre o real retorno da educação" (BANCO MUNDIAL, 2018a, p.16).

A educação como ótica mercadológica visa atender ao mercado de trabalho $\mathrm{e}$ disponibilizar mão de obra para o aumento da produção do capital. A alteração dos meios de produção alterou as configurações da educação. Puziol e Moreira (2009) pontuam que a Teoria do Capital Humano presente em recomendações de organismos internacionais é expressão das relações de produção. Pode-se afirmar que essa teoria apresenta "[...] encaminhamentos que consideraram a educação um investimento capaz de promover o desenvolvimento econômico dos países e explicar suas desigualdades, por meio da vinculação ao trabalho sob uma perspectiva mercadológica" (PUZIOL; MOREIRA, 2009, p. 1), sendo assim:

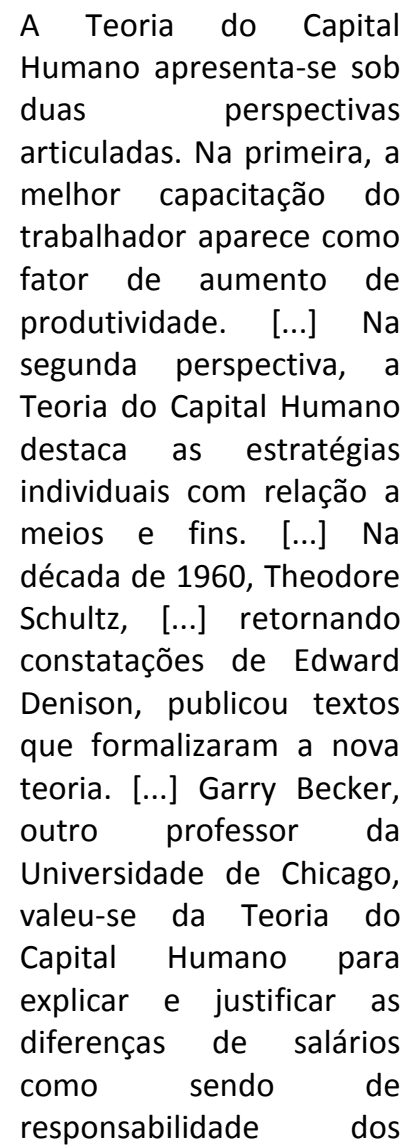

próprios trabalhadores (CATTANI, 2002, p. 50,5153, apud, PUZIOL; MOREIRA, 2009, p. 3).

$\mathrm{Na}$ visão do $\mathrm{BM}$, a educação como ferramenta para fomentar o mercado de trabalho, fornecendo mão de obra para o Brasil está enfrentando uma crise de aprendizagem: apesar de gastos generosos com educação e altos níveis de matrícula na escola, os jovens não estão adquirindo competências que os tornarão trabalhadores competitivos (BANCO MUNDIAL, 2018a), completa ainda que "As deficiências de aprendizagem são cumulativas e começam cedo no percurso escolar dos estudantes, levam à falta de interesse em construir capital humano e motivam 0 abandono escolar entre muitos adolescentes" (BANCO MUNDIAL, 2018a, p. 18), é a educação na visão neoliberal, que objetiva formar indivíduos flexíveis e adaptados para empregos e não formar sujeitos como seres sociais atuantes e pensantes. Cada vez mais precarizados, os trabalhadores, diante da nova era de precarização estrutural do trabalho, tende a ser formado na escola para se adaptar às mudanças estruturais do mundo do trabalho, apontadas por Antunes (2018) como sendo:

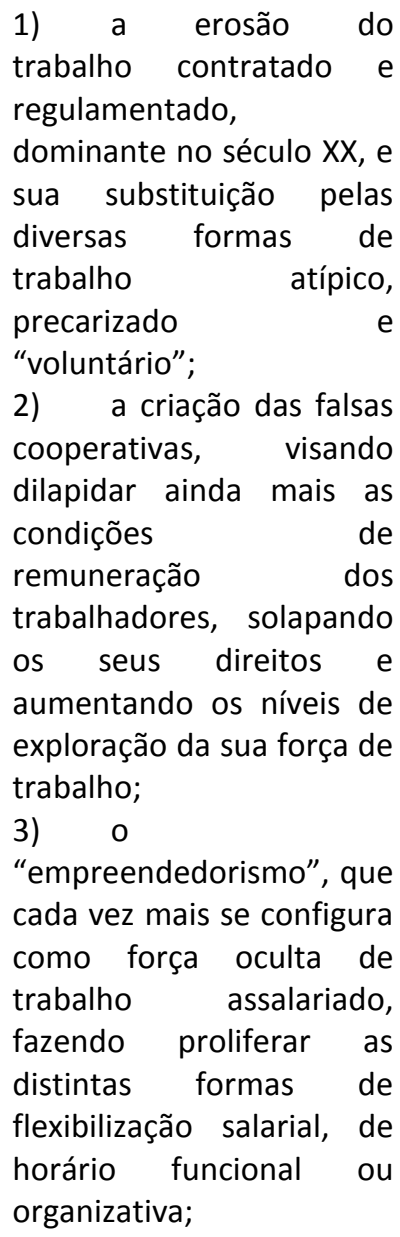


4) a degradação ainda mais intensa do trabalho imigrante em escala global (ANTUNES, 2018, p. 76)

Discursos coerentes com a mercantilização da educação e a mundialização do capital, que visam a manutenção desse sistema, operando via cortes para a educação são recorrentes e passam a fazer parte do corpus da reforma educativa no Brasil, juntamente com recomendações pautadas para além do conhecimento, há uma ênfase às "competências cognitivas, socioemocionais e técnicas" (BANCO MUNDIAL, 2018a, p.10). A Teoria do Capital Humano presente nas orientações do BM "se preocupa exclusivamente com a educação como formadora de força de trabalho, na qual esse investimento educacional traga retorno financeiro para o país, e colabore com o seu desenvolvimento" (ALVES; PUZIOL; MOREIRA, 2009 , p. 10), Como pode se comprovar o relatório de consultoria do BM retrata uma nova perspectiva para a atual configuração da educação, enfatizando as competências:

[...] considerando a
retração econômica que o
país sofreu, confere nova
urgência à agenda de
políticas de competências
e emprego, mas com
ênfase na produtividade
futura dos trabalhadores,
e acentua o foco no
engajamento dos jovens
na escola e no trabalho. A
premissa é que um país
que não consegue
oferecer oportunidades a
seus jovens para que se
engajem, construam e
apliquem seus talentos e
competências encontra-se
em aguda desvantagem
para sustentar seu
desenvolvimento e atingir
alta renda ao passar pela
última etapa de sua
transição demográfica
(BANCO MunDIAL, 2018a,
p. 12).

O foco do documento ao recomendar uma reforma educativa para a juventude brasileira se ancora na análise de que "O Brasil está enfrentando uma crise de aprendizagem: apesar de gastos generosos com educação e altos níveis de matrícula na escola, os jovens não estão adquirindo competências que os tornarão trabalhadores competitivos" (BANCO MUNDIAL, 2018a, p. 17). Nesse sentido o documento apresenta recomendações que permeiam as seguintes categorias recorrentes: competências (cognitivas, analíticas, socioemocionais, técnicas, digitais), capital humano, engajamento econômico, empregabilidade, empreendedorismo e produtividade (BANCO MUNDIAL, 2018).

\section{O Relatório sobre o Desenvolvimento} Mundial: Aprendizagem para realizar a promessa da educação, publicado em 2018 pelo BM, é outro documento categórico em apontar que "Sem aprendizagem, a educação não cumpre plenamente suas promessas como impulsora, tanto na eliminação da pobreza como da prosperidade compartilhada" (BANCO MUNDIAL, 2018b, p. 1). O BM expõe dados agravantes da educação brasileira ao enfatizar que "Embora as aptidões de jovens brasileiros de 15 anos tenham melhorado, se o sistema continuar a progredir no ritmo atual, os jovens levarão 75 anos para atingir a pontuação média em matemática dos países ricos. No campo da leitura, levará mais de 260 anos" (BANCO MUNDIAL, 2018b, p. 1).

O objetivo dos Relatórios sobre o Desenvolvimento Mundial publicado pelo banco desde 1990 é expor o panorama econômico dos países membros a fim de elucidar reformas que julgam necessárias para o desenvolvimento da economia mundial. Os relatórios começaram a ser publicados em 1990 apresentando um período pós-crise do capital. O primeiro relatório World Development Report (1978) ${ }^{9}$ apresentava os dados sobre a pobreza agravante nos países periféricos e orientações pra a erradicação dessa situação. Percebe-se que em vinte oito anos, os relatórios mantiveram essa característica de estudos técnicos com orientações aos países para erradicar a pobreza, o que têm modificado são os caminhos para tal e a ênfase dada a cada relatório desenvolvido. Em alguns fica nítida a ênfase nos aspectos educacionais, como o relatório de 2018 que evidencia a focalização na aprendizagem.

Com informações colhidas no site do próprio banco encontramos o seguinte discurso “Entre 2003 e 2013, o Brasil viveu uma década de progresso econômico e social em que mais de 26

\footnotetext{
${ }^{9}$ Relatório de Desenvolvimento Mundial
} 
milhões de pessoas saíram da pobreza. Restaurar a sustentabilidade fiscal é o desafio econômico mais urgente para o Brasil" (WORLD BANK, 2019). Com a intenção de "restaurar a sustentabilidade fiscal", os relatórios aderiram às novas orientações, de cortes e recessão nos investimentos dos serviços públicos.

Restaurar
sustentabilidade fiscal é o
desafio econômico mais
urgente para o Brasil. Para
lidar com a dinâmica da
dívida insustentável, o
governo adotou a Emenda
Constitucional 95/2016
que limita o crescimento
da despesa pública. Esta
emenda implica um ajuste
fiscal de 5\% do PIB até
2024 e estabiliza a dívida
em cerca de 89\% do PIB
em $2026 . \quad$ A
implementação desse
ajuste fiscal requer o alívio
da rigidez que afeta os
gastos públicos e os
mecanismos de vinculação
de receita, que tornam
obrigatórios mais de 90\%
dos gastos primários do
governo federal. Além
disso, exigirá uma reforma
abrangente da seguridade
social para limitar o
aumento projetado para o
déficit da previdência
(WORLD BANK, 2019).

Com cortes significativos para a educação, o setor privado ganha espaço para atuar em instituições públicas. De acordo com o BM, para o Brasil sair da crise instaurada "exige melhorar a capacidade de planejamento no nível do governo, melhorar o ambiente regulatório e alavancar recursos privados para financiar investimentos" (WORLD BANK, 2019).

A educação colocada na ótica mercadológica tem como princípio alavancar a economia. Dessa forma o Relatório sobre o Desenvolvimento Mundial: Aprendizagem para realizar a promessa da educação (2018) apresenta a "crise da aprendizagem" e os fatores que a influenciam, bem como aqueles que podem saná-la. Formação de professores, o uso de recursos e tecnologia, uma boa gestão e liderança, o alinhamento de interesses políticos em prol do desenvolvimento da aprendizagem são propostas para reverter essa situação alarmante e preocupante. Na visão do banco "A escolaridade sem aprendizagem não é apenas uma oportunidade desperdiçada, mas também uma grande injustiça" (BANCO MUNDIAL, 2018b, p. 1).

Salienta as recomendações do BM no relatório, que o indivíduo precisa ter oportunidades de aprender e para isso é necessário fornecer subsídios, pois o fato de estar na escola não garante o ato de aprender. Em busca de solucionar o fracasso escolar e a não aprendizagem efetiva dos alunos expostos nas avaliações externas, o BM apresenta orientações a serem seguidas por seus países membros, propondo uma série de medidas, dentre elas, a ênfase no gerenciamento responsável das escolas, privatizações e reformas fiscais (BANCO MUNDIAL, 2018b).

Em 29 de agosto de 2018 intensificaramse orientações ao setor educacional diante da crise e do descaso na educação, o BM publicou um outro documento intitulado Por um ajuste justo com crescimento compartilhado: Uma agenda de reformas para o Brasil (2018), no qual pela primeira vez um documento é destinado "[...] à sociedade brasileira e especificamente aos candidatos à presidência e sua equipe econômica na eleição de 2018. Ele apresenta o diagnóstico do Banco Mundial para os principais desafios de desenvolvimento econômico e social do Brasil e propõe um possível caminho para enfrentá-los" (BANCO MUNDIAL, 2018c, p. 03).

Ressalta o documento que "[...] o (a) presidente eleito (a) deverá ter um plano coerente e um forte mandato eleitoral" O BM interpretou o contexto das eleições presidenciais de 2018 da seguinte forma:

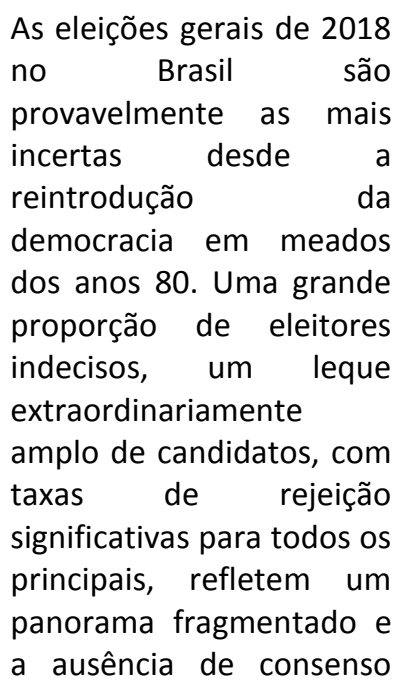


sobre um projeto nacional para o Brasil (BANCO MUNDIAL, 2018c, p. 03).

O documento apresenta argumentos que em sua ótica devem ser considerados pelo governo eleito a fim de manter um "forte mandado eleitoral", no qual é necessário reformas para enfrentar os desafios enfrentados. O diagnóstico realizado apresenta 3 desafios:

o primeiro é o grande desequilíbrio fiscal que teve início em 2012 e que agora representa uma ameaça iminente à retomada do crescimento e à manutenção da estabilidade

macroeconômica. A dívida pública brasileira aumentou de $54 \%$ para $74 \%$ do PIB em apenas cinco anos e está projetada para dobrar novamente na próxima década se não houver mudança nas políticas. 0 segundo desafio é a falta do crescimento sustentado da produtividade, o que coloca em risco futuros aumentos da renda per capita devido à projetada redução do crescimento da força de trabalho no país. A produção brasileira por trabalhador aumentou apenas $0,7 \%$ por ano desde meados dos anos 90, um décimo da produção da China e apenas metade da média dos países da OCDE. 0 terceiro desafio é que o Estado brasileiro tem cada vez mais dificuldade de oferecer serviços públicos básicos, apesar de suas grandes dimensões. 0 Brasil arrecada mais impostos do que um país de porte médio da OCDE. No entanto, a crescente epidemia de violência, a estagnação nos resultados da educação e a incapacidade de prover serviços de saneamento a milhões de brasileiros são apenas alguns dos sintomas do fracasso do estado que exigirão mudanças fundamentais de governança pública (BANCO MUNDIAL, 2018c, p.4, grifos nossos)

Retomando ideias do documento encomendado em 2017, segue na mesma perspectiva de que o Brasil é um país que "gasta mais do que pode" na área social e a solução para essa situação são reformas nos serviços públicos. Pontua que investimentos na educação são importantes para o crescimento econômico do país aborda ainda que "Os investimentos em educação e na aprendizagem ao longo da vida, por sua vez, são componentes centrais do processo de melhoramento do capital humano de um país" (BANCO MUNDIAL, 2018c, p.32).

Alguns argumentam que a lacuna que persiste nos resultados educacionais confirma que o Brasil investe pouco em educação. Foi essa preocupação que originalmente motivou a vinculação de $25 \%$ das receitas estaduais $\mathrm{e}$ municipais à educação, e que foi posteriormente complementada por uma meta de gastos de $10 \%$ do PIB. Nós argumentamos, no entanto, que não é possível melhorar a qualidade da educação simplesmente gastando mais dinheiro. O Brasil já gasta $6,6 \%$ do PIB em educação - mais do que a média dos países da OCDE e muito mais do que muitos países de renda média, incluindo China, Rússia e Chile, que apresentam resultados consideravelmente melhores (BANCO MUNDIAL, 2018c, p.33).

Desse modo, o documento lançado na época das eleições presidências de 2018 também segue a mesma perspectiva, apresentando um 
panorama caótico e soluções por meio de reformas pautadas em ajustes e cortes de gastos na área social e ações privadas. "A discrepância entre o peso do setor público e a qualidade dos serviços oferecidos aos cidadãos indica que as ineficiências são enormes" (BANCO MUNDIAL, 2018c, p.37). Continua pontuando que "Muito pode ser aprendido a partir dessas experiências, mas elas terão que ser adaptadas às novas realidades de baixo orçamento e procurar novas parcerias no setor privado" (BANCO MUNDIAL, 2018c, p.38).

\section{CONCLUSÃO}

Os documentos do Banco Mundial selecionados para a análise documental, a saber Prioridades Y Estrategias para la Educacion - PEE (1995), Um Ajuste Justo: Análise da eficiência e equidade do gasto público no Brasil - AJ (2017), Competências e empregos: uma agenda para a juventude: síntese de constatações, conclusões $e$ recomendações de políticas - CE (2018), Relatório sobre o Desenvolvimento Mundial- Aprendizagem para Realizar a Promessa da Educação: síntese RDM (2018) e Por um ajuste justo com crescimento compartilhado: uma agenda de reformas para o Brasil - PAJCC (2018), revelaram que no período de análise 2016 a 2018, as recomendações do $\mathrm{BM}$ que estiveram presente desde a década de 1990 ainda demarcam o delineamento das atuais reformas.

Em especial o documento Prioridades $Y$ Estrategias para la Educacion (1995) lançou bases teóricas ancoradas no neoliberalismo que no atual período se fazem presentes em recomendação e medidas econômicas de forma mais austeras para o Brasil. De forma bastante presente os documentos lançados em 2017 e 2018 são prioritariamente exclusivos o Brasil, forma encomendados pelo governo brasileiro resultam de consultorias do BM, abordam com ênfase na economia, desenvolvimento sustentável, formação da juventude e educação brasileira.

Nas análises efetuadas nessa pesquisa é possível explicitar as categorias políticas recorrentes nos quatro documentos, conforme o quadro comparativo:

Quadro 01. Categorias políticas recomendadas pelo Banco Mundial nos documentos selecionados (20162018)

\begin{tabular}{|c|c|c|c|c|}
\hline PPE (1995) & $\begin{array}{l}\text { Ajuste Justo - AJ } \\
\text { (2017) }\end{array}$ & $\begin{array}{ll}\text { Competências } & \text { e } \\
\text { Empregos - CE(2018) }\end{array}$ & RDM (2018) & PAJCC (2018 \\
\hline $\begin{array}{l}\text { Equidade } \\
\text { Focalização na } \\
\text { pobreza, } \\
\text { Privatização dos } \\
\text { serviços públicos } \\
\text { Participação } \\
\text { Parcerias }\end{array}$ & $\begin{array}{l}\text { Eficiência } \\
\text { Equidade } \\
\text { Redução } \\
\text { gastos de } \\
\text { Ajustes } \\
\text { Privatização } \\
\text { Focalização }\end{array}$ & $\begin{array}{l}\text { Competências } \\
\text { (cognitivas, analíticas, } \\
\text { socioemocionais, } \\
\text { técnicas, digitais) Capital } \\
\text { Humano Engajamento } \\
\text { econômico } \\
\text { Empregabilidade } \\
\text { Empreendedorismo } \\
\text { Produtividade }\end{array}$ & $\begin{array}{l}\text { Sustentabilidade } \\
\text { Fiscal } \\
\text { Crise da } \\
\text { aprendizagem } \\
\text { Gerenciamento } \\
\text { Privatizações } \\
\text { Reformas fiscais }\end{array}$ & $\begin{array}{l}\text { Crescimento } \\
\text { econômico } \\
\text { Sustentabilidade } \\
\text { Governança } \\
\text { Capital Humano } \\
\text { Ajustes } \\
\text { Redução de } \\
\text { gastos públicos }\end{array}$ \\
\hline
\end{tabular}

Fonte: Elaborado pelas autoras (2018).

As categorias expostas no mapeamento apresentado no quadro 01 demonstram que o conteúdo das recomendações do BM para a política de reforma educacional se pauta essencialmente na visão econômica e na lógica mercadológica e produtiva exigida na tendência atual do trabalho material onde se tem produzido em larga escala o bolsão de desempregados, dos chamados trabalhadores sobrantes e descartáveis. Em paralelo a esse contexto, se produz novos modos de extração do sobre trabalho, que se exige uma adaptabilidade dos currículos escolares e mudança da atuação dos professores, na busca por formar trabalhadores altamente adaptados e qualificados às exigências impostas pelas tecnologias da informação e comunicação (TICS) e competências que agregam valor diante do contexto crescente da informalidade do mercado de trabalho, caracterizada por contratos temporários, ausência de estabilidade, trabalhos dentro ou fora dos espaços produtivo das empresas, atividades temporárias, eventuais e contingenciais (ANTUNES, 2018).

Concluímos que em busca de atender as demandas do mercado internacional as reformas educacionais caminham paralelamente às ideias neoliberais que no contexto de crise econômica e 
política se intensificaram. As medidas tomadas para a construção dessas reformas seguem ditames do Banco Mundial e acatam medidas neoliberais que visam a formação de um trabalhador a serviço do capital. O cenário caótico que a política brasileira enfrenta são reflexos de uma conjuntura capitalista que resultam em um aumento da desigualdade social. Propostas que desvalorizam a educação tornando-a um mero produto mercadológico não condizente com o seu principal valor de emancipação humana.

\section{REFERÊNCIAS}

ADRIÃO, Theresa. Dimensões e formas da privatização da educação no Brasil: caracterização a partir de mapeamento de produções nacionais e internacionais. Currículo sem Fronteiras, v. 18 , n. 1 , p. $8-28$, jan./abr. 2018. Disponível em: http://www.curriculosemfronteiras.org/vol18iss1 articles/adriao.pdf. Acesso em 01 dez. 2018.

ALVES, Giovanni. Notas sobre o Golpe de 2016 no Brasil neodesenvolvimentismo ou crônica de uma morte anunciada. In: LUCENA, Carlos; PREVITELI, Fabiane Santana; LUCENA, Lurdes (Org.). A crise da democracia brasileira. Uberlândia: Navegando Publicações, 2017, p.129147.

ALVES, Giovanni; MOREIRA, Jani; PUZIOL, Jeinni. Educação profissional e ideologia das competências: elementos para uma crítica da nova pedagogia empresarial sob a mundialização do capital. Revista Educere et Educare, v. 4, n. 8, p. 45-59, jul./dez. 2009. Disponível em:

http://e-

revista.unioeste.br/index.php/educereeteducare/ article/view/2281/2808. Acesso em 02 dez. 2018.

AMARAL, Nelson Cardoso. Uma análise do documento: "Um Ajuste Justo: análise da eficiência e equidade do gasto público no Brasil". Goiânia: Universidade Federal de Goiás, 2017.

ANTUNES, Ricardo. A era das contrarrevoluções e o novo estado de exceção. In: LUCENA, Carlos; PREVITELI, Fabiane Santana; LUCENA, Lurdes (Org.). A CRISE da democracia brasileira. Uberlândia: Navegando Publicações, 2017, p.5361.
ANTUNES, Ricardo. 0 privilégio da servidão: o novo proletariado de serviços na era digital. Boitempo: São Paulo, 2018.

BALL, Stephen J. Educação Global S. A.: novas redes de políticas e o imaginário neoliberal. Tradução de Janete Bridon. Ponta Grossa, Brasil: UEPG, 2014.

BANCO MUNDIAL. Prioridades y estrategias para la educacion: Examen Del Banco Mundial. Washington, 1995. Disponível em < http://documentos.bancomundial.org/curated/es 1715681468329483128/Prioridades-yestrategias-para-la-educacion-examen-del-BancoMundial> Acesso em: 11 mai. 2019

BANCO MUNDIAL. Um Ajuste Justo: Análise da eficiência e equidade do gasto público no Brasil. Brasília, 2017. Disponível em < http://documents.worldbank.org/curated/en/88 4871511196609355/pdf/121480-REVISEDPORTUGUESE-Brazil-Public-Expenditure-ReviewOverview-Portuguese-Final-revised.pdf > Acesso em: 11 mai. 2019

BANCO MUNDIAL. Competências e empregos: uma agenda para a juventude: síntese de constatações, conclusões e recomendações de políticas. Brasília, 2018a. Disponível em < http://documents.worldbank.org/curated/pt/953 $891520403854615 / \mathrm{pdf} / 123968-W P-P U B L I C-$ PORTUGUESE-P156683-

CompetenciaseEmpregosUmaAgendaparaaJuvent ude.pdf> Acesso em: 11 mai.2019

BANCO MUNDIAL. Relatório sobre o Desenvolvimento Mundial de 2018: Aprendizagem para Realizar a Promessa da Educação. Washington, 2018b. Disponível em < https://www.worldbank.org/pt/news/pressrelease/2017/09/26/world-bank-warns-oflearning-crisis-in-global-education $>$ Acesso em: 11 mai. 2019

BANCO MUNDIAL. Por um ajuste justo com crescimento compartilhado: uma agenda de reformas para o Brasil. Brasília, 2018c. Disponível em

http://pubdocs.worldbank.org/en/156721534876 313863/Sum\%C3\%A1rio-Notas-dePol\%C3\%ADtica-P\%C3\%BAblica.pdf> Acesso em: 11 mai. 2019 
BOITO JUNIOR, Armando. A Crise Política do Neodesenvolvimentismo e a Instabilidade da Democracia. Crítica Marxista, n. 42, p.155-162, 2016.

CUNHA, Luiz Antônio. O projeto reacionário da educação. $2016 . \quad$ Disponível em: http://www.luizantoniocunha.pro.br/uploads/ind ependente/ProjReacEd livro.pdf. Acesso em: 03 dez. 2018.

CHAUI, Marilena. A nova classe trabalhadora brasileira e a ascensão do conservadorismo. In: JINKINGS, Ivana; DORIA, Kim; CLETO, Murilo (org.). Por que gritamos golpe? Para entender o impeachment e a crise política no Brasil. São Paulo: Boitempo, 2016, p. 15-22.

GALLEGO, Esther Solano. 0 ódio como política: a reinvenção das direitas no Brasil. São Paulo: Boitempo, 2018.

GENTILI, P. Neoliberalismo e educação: manual do usuário. In: SILVA, T. T. da; GENTILI, P. (Orgs.). Escola S.A.: quem ganha e quem perde no mercado educacional do neoliberalismo. Brasília, DF: CNTE, 1996, p. 9-49.

LEVITSKY, Steven; ZIBLATT, Daniel. Como as democracias morrem. Rio de Janeiro: Zahar, 2018.

MORAES, Reginaldo C. Neoliberalismo - de onde vem para onde vai? São Paulo: Editora Senac, 2001.

MOREIRA, Jani Alves da Silva. Reformas Educacionais e Políticas Curriculares para a Educação Básica: prenúncios e evidências para uma resistência ativa. Germinal: Marxismo e Educação em Debate, Salvador, v. 10, n. 2, p. 199-213, Ago. 2018. Disponível em: https://portalseer.ufba.br/index.php/revistagerm inal/article/view/27355. Acesso em: $02 \mathrm{dez}$. 2018.

MOREIRA, Jani Alves da Silva; SILVA, Renata Valério. Políticas para a formação de professores e as recomendações do Banco Mundial: interfaces com o contexto atual da formação de professores alfabetizadores no Brasil. Práxis Educativa, Ponta Grossa, v. 11, n. 1, p. 37-61, jan./abr. $2016 . \quad$ Disponível em: http://www.revistas2.uepg.br/index.php/praxise ducativa/article/view/7198/4756 Acesso em: 02 dez. 2018.

PANSARDI, Marcos Vinícius. A Formação de Professores e o Banco Mundial. In: SIMPÓSIO BRASILEIRO DE POLÍTICA E ADMINISTRAÇÃO DA EDUCAÇÃO, 24. , 2009. Cadernos [...]. Porto Alegre: ANPAE, 2009. Disponível em: www.anpae.org.br/congressos antigos/simposio 2009/201.pdf. Acesso em: 02 dez. 2018.

PEREIRA, João Márcio Mendes. Topoi, v. 11, n. 21, p. 260-280, jul.-dez. 2010. Disponível em: http://www.scielo.br/pdf/topoi/v11n21/2237101X-topoi-11-21-00260.pdf Acesso em: $02 \mathrm{dez}$. 2018.

PUZIOL, Jeinni; MOREIRA, Jani Alves da Silva. Capital humano e educação sob a perspectiva da Unesco no Brasil. In: SEMINÁRIO DO HISTEDBR, 8., 2009. Anais [...], Campinas-SP: UNICAMP, $2009 . \quad$ Disponível em: http://www.histedbr.fe.unicamp.br/acer histedb r/seminario/seminario8/ files/p3bVDis.pdf

Acesso em: 01 dez. 2018

SAVIANI, Dermeval. A crise política no Brasil, o golpe e o papel da educação na resistência e na transformação. In: LUCENA, Carlos; PREVITELI, Fabiane Santana; LUCENA, Lurdes (Org.). A CRISE da democracia brasileira. Uberlândia: Navegando Publicações, 2017, p.215-232.

SHIROMA, Eneida. GARCIA, Rosalba Maria Cardoso. CAMPOS, Roselane Fátima. Conversão das "almas" pela liturgia da palavra: uma análise do discurso do movimento Todos pela Educação, p. 222 a 248. In: BALL, Stephen, MAINARDES, Jefferson. (orgs) Políticas educacionais: questões e dilemas. São Paulo: Cortez, 2011.

SOUZA, Ângelo Ricardo de. Reformas educacionais: descentralização, gestão e autonomia escolar. Educar, Curitiba, n. 22, p. 1749, 2003.

WAISMANN, Moisés; CORSETTI, Berenice. O Banco Mundial e as políticas públicas para o ensino superior no Brasil. Revista Educação Unisinos, v. 3, n. 18, p.331-341, set./dez., 2014. Disponível 
http://www.redalyc.org/html/4496/4496443440

13/. Acesso em: 01 dez. 2018.

WORLD BANK. Brasil: aspectos gerais. 2019.

Disponível

em:

https://www.worldbank.org/pt/country/brazil/ov

erview Acesso em: 11 mai. 2019

VALIM, Rafael. Estado de Exceção: a forma jurídica do neoliberalismo. São Paulo: Editora Contracorrente, 2017.

Submetido: 08/08/2018

Correções obrigatórias: 06/11/2018

Aceite final: 17/01/2019 